\title{
Effects of High Salinity Stress on the Survival, Gill Tissue, Enzyme Activity and Free Amino Acid Content in Razor Clam Sinonovacula constricta
}

\author{
Wei Cao ${ }^{1,2,3 \dagger}$, Siqi Bi ${ }^{1,4+}$, Changfeng Chi3 ${ }^{3}$, Yinghui Dong ${ }^{5}$, Sudong Xia ${ }^{4}$, Zhihong Liu'1,2, \\ Liqing Zhou 1,2, Xiujun Sun 1,2, Yusong Geng ${ }^{1,4}$ and Biao Wu ${ }^{1,2 *}$
}

1 Key Laboratory of Sustainable Development of Marine Fisheries, Ministry of Agriculture and Rural Affairs, Yellow Sea Fisheries Research Institute, Chinese Academy of Fishery Sciences, Qingdao, China, ${ }^{2}$ Laboratory for Marine Fisheries Science and Food Production Processes, Qingdao National Laboratory for Marine Science and Technology, Qingdao, China, ${ }^{3}$ National Engineering Research Center of Marine Facilities Aquaculture, Zhejiang Ocean University, Zhoushan, China, ${ }^{4}$ Key Lab of Aqua-Ecology and Aquaculture, Department of Fishery Science, Tianjin Agricultural University, Tianjin, China, ${ }^{5}$ Key Laboratory of Aquatic Germplasm Resources of Zhejiang, Zhejiang Wanli University, Ningbo, China

\section{OPEN ACCESS}

Edited by:

Huang Wei,

Second Institute of Oceanography, Ministry of Natural Resources, China

Reviewed by:

Zhiguo Dong,

Jiangsu Ocean University, China

Zonghe Yu,

South China Sea Institute

of Oceanology, Chinese Academy

of Sciences (CAS), China

*Correspondence:

Biao Wu

wubiao@ysfri.ac.cn

tThese authors have contributed equally to this work and share first authorship

Specialty section:

This article was submitted to Marine Fisheries, Aquaculture

and Living Resources,

a section of the journal

Frontiers in Marine Science

Received: 20 December 2021 Accepted: 25 January 2022

Published: 16 February 2022

Citation:

Cao W, Bi S, Chi C, Dong Y, Xia S, Liu Z, Zhou L, Sun X, Geng Y and Wu B (2022) Effects of High Salinity

Stress on the Survival, Gill Tissue, Enzyme Activity and Free Amino Acid Content in Razor Clam Sinonovacula constricta. Front. Mar. Sci. 9:839614.

doi: 10.3389/fmars.2022.839614
Salinity can affect the physiological and productive characteristics of bivalves. The razor clam Sinonovacula constricta naturally distributing in intertidal zones and estuarine waters is extensively cultured in China. High-salinity is a serious threat to its culture, especially in pond culture model. Here, we investigated the effects of high-salinity on the survival, gill tissue, enzyme activity and free amino acid content of $S$. constricta. Individuals were randomly divided into six groups treated with different salinities of 20, $25,30,35,40$, and 45 ppt. The median lethal salinity calculated by linear regression and probit analysis methods were similar, with $46.61,43.17,36.99,35.99$, and 34.99 ppt by linear regression, while $44.63,42.87,38.45,37.32$, and 36.17 ppt by probit analysis at $72,96,120,144$, and $168 \mathrm{~h}$, respectively. Furthermore, paraffin section revealed that the gill of razor clam shrunk quickly under high-salinity and dissolved at $48 \mathrm{~h}$ under salinity of 40 ppt, but not under 30 ppt. In addition, the activities of three enzymes including $\mathrm{Na}^{+}$$\mathrm{K}^{+}$-ATPase, acid phosphatase and alkaline phosphatase changed significantly under high-salinity. Besides, the contents of total free amino acids (TFAAs) in the gill tissues were $61.25 \pm 1.58,89.36 \pm 4.18$, and $111.98 \pm 1.46 \mathrm{mg} \cdot \mathrm{g}^{-1}$ at salinity of 20,30 , and $40 \mathrm{ppt}$, respectively, indicating increasing TFAA contents with salinity. Notably, several amino acid species including taurine, alanine, proline, glycine and glutamic showed significantly changed contents in response to salinity variation, suggesting these amino acids might play an important role in razor clam's adaptation to salinity stress. Combining all these results, it was referred that razor clams may adapt to moderately high-salinity of 30 ppt in a short time through osmotic adjustment. Although a small proportion of individuals could survive under the salinity of $35 \mathrm{ppt}$, the death of most individuals still suggested it can hardly be accepted in aquacultural production. Notably, living under a salinity of $40 \mathrm{ppt}$ for more than $48 \mathrm{~h}$ could cause great damage to razor clams. Therefore, the seawater salinity is recommended to be lower than 30 ppt for S. constricta aquaculture. Overall, this study provides guidance for the culture and breeding of high-salinity tolerant razor clams. 


\section{INTRODUCTION}

Salinity is an important environmental factor that affects the osmoregulation, immune defense and survival of aquatic organisms (Pechenik et al., 2000; Vargas-Chacoff et al., 2015). Different from open seas with relatively stable salinity levels, intertidal zones, estuaries and land-based seawater ponds are characterized by varying salinity levels (Berger and Kharazova, 1997). The changes of salinity due to high-temperature evaporation, seasonal heavy rainfall and human activities can cause damage and even death to aquatic organisms (Gagnaire et al., 2006; Munari et al., 2011; Carregosa et al., 2014). Most bivalves have poor mobility and they have to adapt to the frequent fluctuations of salinity in their residing environment. Although the bivalves have evolved some regulatory mechanisms to resist salinity stress, the population still begin to deteriorate when stressed by acute changes in salinity (Chen et al., 2021).

Salinity stress can lead to morphological, physiological, biochemical and metabolic changes (e.g., reduction of feeding activity, growth rate and immune defense) in living organisms (Carregosa et al., 2014). As a respiratory organ, gill is in direct contact with seawater and thus represents a major site for osmotic water loss and diffusive gain of salts (Laverty and Skadhauge, 2012; Luzio et al., 2021). Since it is an important organ responsible for osmoregulation, the changes of gill tissue structure can greatly affect the aforementioned function (Allen et al., 2011). As an important indicator, the morphological changes of gills have been explored in a variety of aquatic animals by tissue section techniques (Wang and Hu, 2009; Wang et al., 2016; Gao et al., 2019). For example, the space between gill lamellae of purple Washington clam Saxidomus purpurata changes significantly under different salinity stresses (Wang et al., 2016). In addition, enzymes such as $\mathrm{Na}^{+}-\mathrm{K}^{+}$-ATPase (NKA), alkaline phosphatase (AKP) and acid phosphatase (ACP) play important roles in aquatic organisms' response to salinity stress. NKA is able to drive the active transport of ions across the membrane against concentration gradient (Lin et al., 2004; Yang et al., 2009). AKP and ACP are important immune factors in biological metabolism (Zhang et al., 2017). They are involved in the transfer reaction of phosphate groups and the balance of energy in the body, and are important indicators to measure the immunity and health status of the body. There are studies concerning the changes of enzyme activities in aquatic economic animals such as Pacific white shrimp Litopenaeus vannamei (Shen et al., 2020) and Jinjiang oyster Crassostrea ariakensis (Shi et al., 2013) under salinity stress. Furthermore, free amino acids (FAAs) are demonstrated to contribute dominantly to intracellular osmolality and cell volume regulation. Under high salinity, aquatic organisms often increase FAA contents by means of new biosynthesis, uptake from the environment, or depolymerization of polypeptide (Heavers and Hammen, 1985). An almost linear relationship between salinity and total FAA content has been observed in blue mussel Mytilus edulis (Lange, 1963), Eastern oyster Crassostrea virginica (Lynch and Wood, 1966; Heavers and Hammen, 1985). Note, however, due to the complexity nature of the regulatory mechanisms of bivalves under salt stress, related studies remain limited. Moreover, previous research mainly concerns with economic species like the manila clam Venerupis philippinarum (Carregosa et al., 2014) and Pacific oyster Crassostrea gigas (Meng et al., 2013). More research is needed to clarify the effects of salinity stresses on other bivalves.

The razor clam, Sinonovacula constricta, is a marine bivalve and naturally distributes in the estuary and intertidal region where salinity is usually lower than that of normal seawater (Chen et al., 2021). As one of the four traditional shellfish species for aquaculture in China, $S$. constricta has become one of the most economically important species as result of its large-scale culture along the coastal areas from Liaoning to Fujian province of China (Peng et al., 2019). Since it can bring better ecological benefits and higher economic income, integrated culture in pond has recently become a popular mode for the razor clam cultivation in northern China. However, water conditions in pond can change greatly due to external environmental factors including drought, high temperature, etc. Although the razor clam can withstand salinity stress to some extent, the acute and dramatic increase in salinity often leads to large-scale mortality of individuals ( $\mathrm{Li}$ et al., 2021). On the other hand, studies suggest that aquatic animals cultured under higher salinity often have better taste and nutrition (Ran et al., 2017; Kumari et al., 2021; Luo et al., 2021), which promotes the breeding of new varieties with high salinity tolerance. However, information on the response of $S$. constricta to high salinity stress is still lacking.

In this study, S. constricta was subjected to high salinity stress and the changes of the survival, gill tissue, enzyme activities and FAA contents of razor clams were analyzed and compared with those under the normal living salinity. The results will provide insights into the regulatory mechanism of razor clams in the adaptation to moderately high salinity and provide useful information for breeding new varieties with highsalinity tolerance.

\section{MATERIALS AND METHODS}

\section{Clams}

Approximately 2,500 wild adult clams $S$. constricta with a shell length of $5.14 \pm 0.38 \mathrm{~cm}$ were obtained from Qingdao city (Shandong Province of China, $36.5900^{\circ} \mathrm{N}, 120.8024^{\circ} \mathrm{E}$ ) where the annual salinity ranges from 18 to $22 \mathrm{ppt}$. Those clams were acclimated for 1 week in an incubator containing aerated seawater (salinity $20 \pm 1 \mathrm{ppt}$; temperature $25 \pm 1^{\circ} \mathrm{C}$; pH 8.0). During acclimation period, the razor clams were fed twice daily with Isochrysis galbana until use.

\section{Salinity Challenge and Tissue Sampling}

The razor clams were randomly divided into six groups (with 180 individuals in each group) and were subjected to different salinity levels of $20\left(\mathrm{~S}_{20}\right), 25\left(\mathrm{~S}_{25}\right), 30\left(\mathrm{~S}_{30}\right), 35\left(\mathrm{~S}_{35}\right), 40\left(\mathrm{~S}_{40}\right)$, and 45 ppt $\left(\mathrm{S}_{45}\right)$ with $\mathrm{S}_{20}$ set as control. The experimental waters with different salt concentrations were obtained by diluting natural seawater with fresh water (without salt) or adding sea salt (Guangzhou Yier Bioengineering Company) to increase the salt concentrations. Three parallel experiments were conducted for each salinity level. The treatment continued for $168 \mathrm{~h}$. The 
mortality of $S$. constricta was measured after 6, 12, 24, 48, 72, 96, 120,144 , and $168 \mathrm{~h}$ of treatment. The gill samples in groups $\mathrm{S}_{20}$, $\mathrm{S}_{30}$, and $\mathrm{S}_{40}$ were collected at $0,6,12,24,48,72,96$, and $120 \mathrm{~h}$ of treatment for paraffin sectioning, enzyme activity detection and FAA content analysis, with three biological replicates for each experiment.

\section{Mortality and Median Lethal Concentration $\left(L C_{50}\right)$ Analysis}

The death of individuals in each group was recorded. The mortality rate was calculated as $\mathrm{N} /\left(\mathrm{N}+\mathrm{N}_{\mathrm{t}}\right) \times 100 \%$, where $\mathrm{N}$ and $\mathrm{N}_{\mathrm{t}}$ represented the numbers of dead and surviving razor clams in each tank at sampling time points, respectively.

The $L C_{50}$ of salinity for razor clam at $72,96,120,144$, and $168 \mathrm{~h}$ were analyzed by linear regression and probit analysis on the basis of mortality data. The calculation formula and method were referred from Hoekstra (1991) and Li et al. (2012).

\section{Tissue Fixation and Biopsy}

The gill samples of each group obtained at $0,6,12,24,48,72,96$, and $120 \mathrm{~h}$ were cut into pieces with a size of about $5 \mathrm{~mm} \times 10 \mathrm{~mm}$ and immersed in Bouin's solution (Sbjbio, Nanjing, China) for fixation of $12 \mathrm{~h}$. After being fixed, the tissues were washed with $70 \%$ ethanol, which was replaced every $24 \mathrm{~h}$ until the solution was colorless, and then dehydrated with $75,80,85,90,95$, and $100 \%$ ethanol in series with $5 \mathrm{~min}$ for each solution. The dehydrated tissue samples were stained with hematoxylin and eosin $(\mathrm{HE})$, and then soaked twice in xylene (15 min each time), followed by paraffin embedding, sectioning, baking, and staining prior to Leica DMI3000B microscopy analysis (Gao et al., 2019).

In order to better explore the structural changes of gill caused by high salinity stress, we measured the gill filament length (GFL), gill filament width (GFW) and gill thickness (GT) of S. constricta (Figure 1) by using the software Toupview 3.7the camera application for the Leica DMI3000B microscopy. We selected a total of 2 or 4 gill filaments at the top and bottom of Figure 1 for measuring GFL and GFW. Thus, each measurement of 1 GT can correspond to 2 or 4 measurement of GFL and GFW. To improve the accuracy of the measurement, GFL, GFW, and GT were detected with approximately 100, 100, and 30 repeats, respectively.

\section{Enzyme Activity Analysis}

The gill samples of each group obtained at $0,6,12,24,48,72$, 96, and $120 \mathrm{~h}$ were homogenized in cold physiological saline at a weight $(\mathrm{g})$ to volume $(\mathrm{mL})$ ratio of 1:9 in an icebox. The homogenates were then centrifuged at $560 \times g$ for $10 \mathrm{~min}$ at $4^{\circ} \mathrm{C}$. Then, the supernatant was transferred to a new container and stored at $-80^{\circ} \mathrm{C}$ for enzyme activity analysis. The activities of enzymes including NKA, ACP, and AKP were detected using corresponding kits (Nanjing Jiancheng Bioengineering Institute, China) according to the manufacturer's instructions and measured by the microplate reader (Thermo Varioskan Flash). NKA activity was determined as described previously by measuring the release of inorganic phosphate at $660 \mathrm{~nm}$, and the enzyme activity unit (U) was expressed as the amount of $1 \mu \mathrm{mol}$

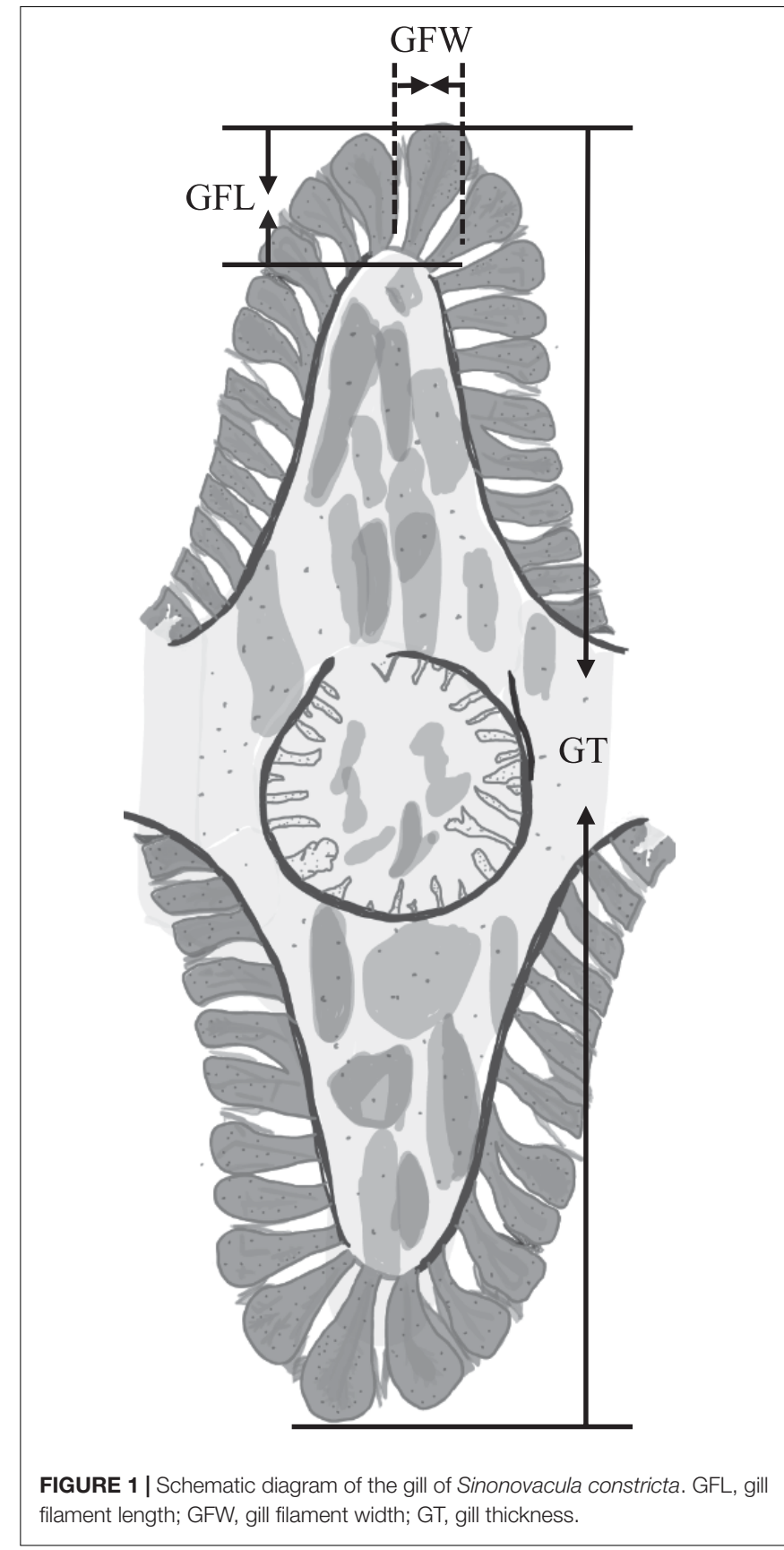

of inorganic phosphorus $(\mathrm{Pi})$ produced by the ATPase per mg of tissue protein decomposing ATP per hour (Chen et al., 2021). $\mathrm{AKP}$ and ACP activities were measured by using disodium phenyl phosphate as the substrate. One unit (U) of AKP and ACP activity was defined as the amount of enzyme in a $1 \mathrm{mg}$ sample necessary for producing $1 \mathrm{mg}$ of nitrophenol for 15 and $30 \mathrm{~min}$ at $37^{\circ} \mathrm{C}$, respectively (Shen et al., 2020).

\section{Free Amino Acid Analysis}

Gills from groups $\mathrm{S}_{20}, \mathrm{~S}_{30}$, and $\mathrm{S}_{40}$ at $48 \mathrm{~h}$ of treatment were selected for FAA content analysis. Before analysis, the gill tissue was freeze-dried for $48 \mathrm{~h}$, and then grinded into powder. Each 
sample with weight of $1 \mathrm{~g}$ was transferred into a $50 \mathrm{~mL}$ tube containing $25 \mathrm{~mL}$ of hydrochloric acid with a concentration of $0.1 \mathrm{M}$, and then subjected to ultrasonic treatment for $30 \mathrm{~min}$. After treatment, the mixed liquid was centrifuged at 3,000 $\times g$ for $15 \mathrm{~min}$. The supernatant was collected while the precipitate was made to undergo the above extraction procedures again. The supernatants from the two extraction processes were mixed and then the final volume was made constant with ultrapure water to $50 \mathrm{~mL}$. Then, $5 \mathrm{~mL}$ of filtrate was accurately obtained and mixed evenly with $2.5 \mathrm{~mL}$ of sulfosalicylic acid (concentration of $60 \mathrm{~g} \cdot \mathrm{L}^{-1}$ ) to react for $5 \mathrm{~min}$. After centrifuged, $1 \mathrm{M}$ sodium hydroxide was used to adjust $\mathrm{pH}$ to about 2.0, $0.02 \mathrm{M} \mathrm{HCl}$ was used to make the mixture volume constant to 50 , and $1 \mathrm{~mL}$ of mixture was analyzed by automatic amino acid analyzer (Amino acid automatic analyzer L-8900, Hitachi High-Tech Corporation).

\section{Statistical Analysis}

The software SPSS 26 was employed for calculation of $L C_{50}$ of salinity and a one-way analysis of variance (ANOVA) and Tukey's test were used for statistical analysis. Differences were considered significant at $P<0.05$. All the results were presented as mean \pm standard deviation (S.D.).

\section{RESULTS}

\section{Effect of High Salinity on the Survival of Sinonovacula constricta}

The mortality rate of the razor clam after high salinity treatment is shown in Figure 2. As can be seen, the mortality rate in the control group $\left(\mathrm{S}_{20}\right)$ remained zero during the whole experiment period, indicating the razor clam individuals used were all in good health. No death occurred in all groups at $6 \mathrm{~h}$ of treatment, and the first death occurred at $12 \mathrm{~h}$ of treatment for the $\mathrm{S}_{45}$ group. With the extension of time, the clams in other groups also began to die because of the salinity stress. Also note that

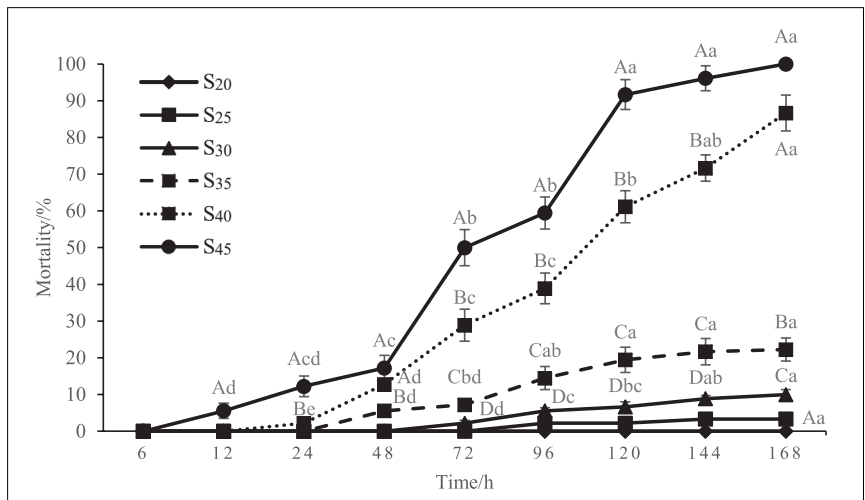

FIGURE 2 | Mortality rate of Sinonovacula constricta at different salinities and time points. Different capital letters represent significant differences between groups treated with different salinity levels at the same time point $(P<0.05)$, and different small letters represent significant differences between different time points for the same group $(P<0.05)$. at each measuring time point, the mortality rate increased with salinity. The mortality rates of groups $S_{25}$ and $S_{30}$ remained significantly lower than that of other high salinity groups. The mortality rate of group $S_{35}$ increased slowly and evenly with stress time. In comparison, the mortality rates of groups $S_{40}$ and $S_{45}$ increased relatively more sharply with stress time. At $72 \mathrm{~h}$ of treatment, the mortality rates of groups $\mathrm{S}_{25}, \mathrm{~S}_{30}, \mathrm{~S}_{35}, \mathrm{~S}_{40}$, and $\mathrm{S}_{45}$ were $0,2.22 \pm 0.79,7.22 \pm 0.79,28.89 \pm 4.37,50.00 \pm 4.91 \%$, respectively, and the mortality rates of groups $S_{40}$ and $S_{45}$ were significantly higher than those of other groups $(P<0.05)$. At $120 \mathrm{~h}$ of treatment, the mortality rates of groups $\mathrm{S}_{25}, \mathrm{~S}_{30}, \mathrm{~S}_{35}$, $\mathrm{S}_{40}$, and $\mathrm{S}_{45}$ increased to $2.22 \pm 0.79,6.67 \pm 1.36,19.44 \pm 3.42$, $61.11 \pm 4.37$, and $91.67 \pm 4.08 \%$, respectively, with significant differences between every two groups $(P<0.05)$. It was worth mentioning that all the razor clams in $S_{45}$ group died at $168 \mathrm{~h}$, with mortality rate of $100 \%$.

The $L C_{50}$ of salinity for $S$. constricta at each sampling time point were assessed using two methods including linear regression equation and probability unit model equation (Tables 1, 2). It was found that the $L C_{50}$ value decreased with increasing stress time. Calculated by linear regression, the $L C_{50}$ of salinity for $S$. constricta at 72, 96, 120, 144, and $168 \mathrm{~h}$ were $46.61,43.17,36.99,35.99$, and $34.99 \mathrm{ppt}$, respectively, while the values were $44.63,42.87,38.45,37.32$, and $36.17 \mathrm{ppt}$ calculated by using probit analysis. As shown, the $L C_{50}$ of salinity calculated by the two methods were similar, indicating that the results were reliable.

\section{Gill Tissue Change in Response to Salinity Stress}

Figure 3 shows the gill tissue structure at different salinity levels and time points. According to the above results, we selected representative micrographs at $6,12,48$, and $96 \mathrm{~h}$ to display the

TABLE 1 | Analysis of $L C_{50}$ salinity for Sinonovacula constricta at different time points using linear regression.

\begin{tabular}{llllll}
\multicolumn{7}{c}{ Time/h Regression equation } & \multicolumn{3}{c}{$\begin{array}{c}\text { Relative } \\
\text { coefficient }\end{array}$} & \multicolumn{2}{c}{ L $\boldsymbol{C}_{\mathbf{5 0}}$ /ppt Lower limit Upper limit } \\
\hline 72 & $y=40.00 x+26.61$ & 0.767 & 46.61 & 38.31 & 54.91 \\
96 & $y=35.68 x+25.33$ & 0.839 & 43.17 & 36.79 & 49.55 \\
120 & $y=22.66 x+25.66$ & 0.829 & 36.99 & 31.94 & 42.04 \\
144 & $y=21.30 x+25.34$ & 0.841 & 35.99 & 31.25 & 40.73 \\
168 & $y=19.20 x+25.39$ & 0.826 & 34.99 & 30.26 & 39.72 \\
\hline
\end{tabular}

TABLE 2 | Analysis of $L C_{50}$ of salinity for Sinonovacula constricta at different time points using probit analysis.

\begin{tabular}{lcccc}
\hline Time/h & Regression equation & LC $_{\mathbf{5 0}} / \mathbf{p p t}$ & Lower limit & Upper limit \\
\hline 72 & $y=0.14 x-6.37$ & 44.63 & 43.65 & 45.85 \\
96 & $y=0.12 x-5.27$ & 42.87 & 41.91 & 44.01 \\
120 & $y=0.19 x-7.14$ & 38.45 & 37.86 & 39.05 \\
144 & $y=0.19 x-7.23$ & 37.32 & 36.41 & 38.27 \\
168 & $y=0.23 x-8.29$ & 36.17 & 35.01 & 37.39 \\
\hline
\end{tabular}




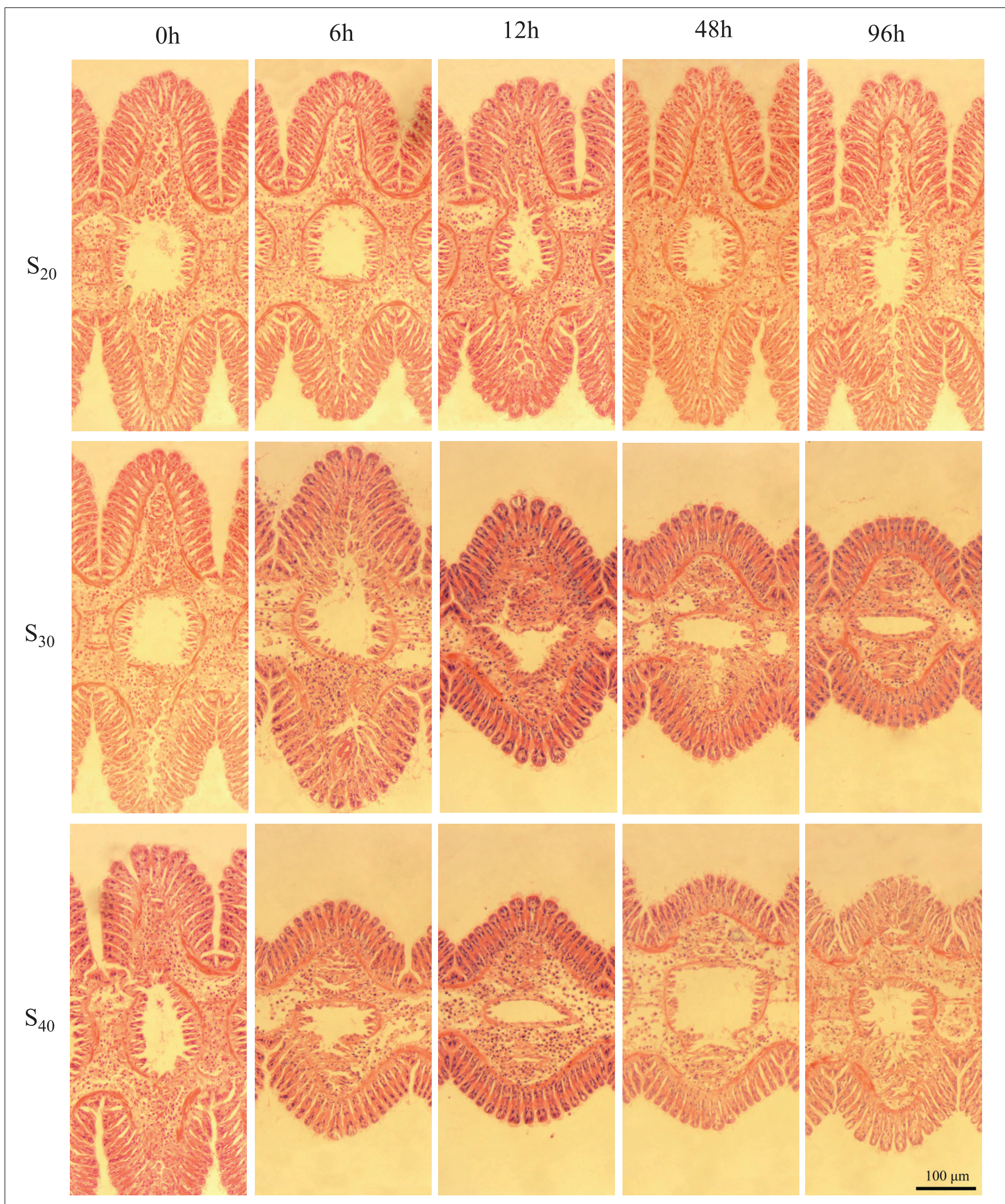

FIGURE 3 | Gill tissue structure of Sinonovacula constricta at different salinities and time points. $\mathrm{S}_{20}$ : Control group; $\mathrm{S}_{30}$ : salinity of 30 ppt; $\mathrm{S}_{40}$ : salinity of 40 ppt. Scale bars are $100 \mu \mathrm{m}$. 
gill structure change. In the control group $\left(\mathrm{S}_{20}\right)$, the histological structure of gill lamella changed little with time, and the gill filaments experienced no shrinkage. In $\mathrm{S}_{30}$, the gill changed little within the first $6 \mathrm{~h}$, but with further extension of stress time the lamella of $S$. constricta contracted as a whole and did not recover. Similarly, in $S_{40}$, the gill tissue changed significantly and the lamella contracted as a whole as the stress time exceeded $6 \mathrm{~h}$. Notably, the gill tissue began to dissolve after $48 \mathrm{~h}$ of treatment, indicating severe pathological changes of the gill.

As shown in Figure 4, the effects of salinity on GFL, GFW, and GT of S. constricta were generally similar. In $S_{20}$, the GFL, GFW, and GT changed little with time. In $S_{30}$, the GFL and GFW decreased significantly after $6 \mathrm{~h}$ of salinity stress treatment $(P<0.05)$. The GFL decreased to the lowest level $(67.45 \pm 7.32$ $\mu \mathrm{m})$ at $24 \mathrm{~h}$ and then rose slowly to the $6 \mathrm{~h}$ level at $96 \mathrm{~h}$ of salinity
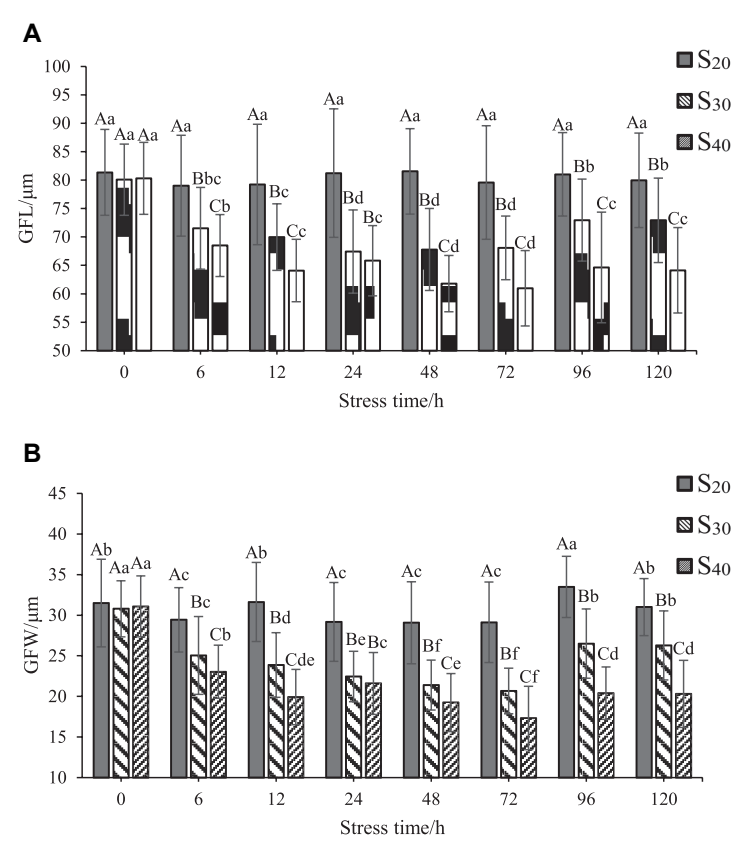

C

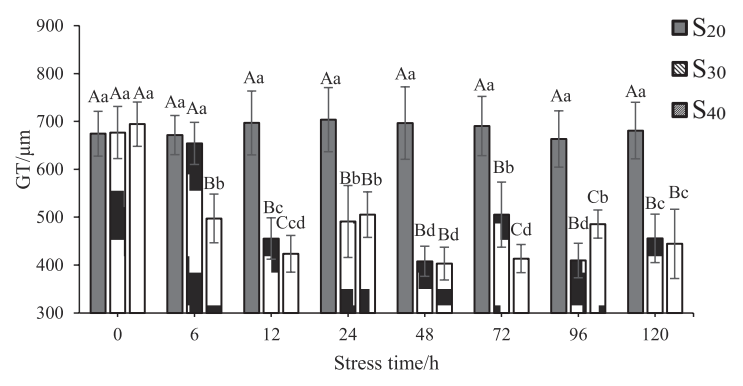

FIGURE 4 | Gill change of Sinonovacula constricta at different salinities and time points. (A) Gill filament length (GFL), (B) Gill filament width (GFW), and (C) Gill thickness (GT) at different salinities and time points. Different capital letters represent significant differences between groups treated with different salinity levels at the same time point $(P<0.05)$, and different small letters represent significant differences between different time points for the same group $(P<0.05)$. treatment. The GFW decreased to the lowest level $(20.67 \pm 2.81$ $\mu \mathrm{m})$ at $72 \mathrm{~h}$ and then rose slowly to the $6 \mathrm{~h}$ level at $96 \mathrm{~h}$ of salinity treatment. The trend of GT with time was different. GT value decreased significantly after $12 \mathrm{~h}$ and then fluctuated with further extension of time, but the value remained significantly lower than that of the control group $(P<0.05)$. In $\mathrm{S}_{40}$, the GFL, GFW, and GT decreased significantly after $6 \mathrm{~h}(P<0.05)$. The GFL and GFW both decreased to the lowest levels $(60.98 \pm 6.62$ and $17.34 \pm 3.90 \mu \mathrm{m}$, respectively) at $72 \mathrm{~h}$ and then rose slowly to the $12 \mathrm{~h}$ level at $96 \mathrm{~h}$. The GT fluctuated with time and remained significantly lower than that of the control group $(P<0.05)$.

\section{Changes of $\mathrm{Na}^{+}-\mathrm{K}^{+}$-ATPase, Acid Phosphatase, and Alkaline Phosphatase Activities in Response to Salinity Stress}

The activities of three enzymes including NKA, ACP, and AKP at different salinity levels and time points are shown in Figure 5. In the control group $\left(\mathrm{S}_{20}\right)$, the NKA activity changed little with time. In groups $S_{30}$ and $S_{40}$, the NKA activity showed different variation characteristics as the treatment time exceeded $6 \mathrm{~h}$. In $S_{30}$, the activity of NKA increased first, reached the highest value of $7.61 \pm 1.14 \mathrm{U} \cdot \mathrm{mg}^{-1}$ at $6 \mathrm{~h}$, and then decreased to the control level at $12 \mathrm{~h}$. With further extension of time (24$120 \mathrm{~h}$ ), the NKA activity remained stable and at a lower level as compared with that of the control group. In $S_{40}$, the trend of NKA activity with time was similar with that of group $S_{30}$ within the first $12 \mathrm{~h}$. However, the NKA activity of group $\mathrm{S}_{40}$ increased back again to the maximum value of $8.77 \pm 0.50$ $\mathrm{U} \cdot \mathrm{mg}^{-1}$ at $24 \mathrm{~h}$ and remained the same level at $48 \mathrm{~h}$, but then decreased sharply and continuously to the lowest value from 72 to $120 \mathrm{~h}$, only accounting for $45.39 \%$ of that at $0 \mathrm{~h}$. All those results indicated that the activity of NKA was induced by high salinity stress, and the $40 \mathrm{ppt}$ salinity level resulted in more significant change in enzyme activity than the 30 ppt salinity level.

ACP activity of $S$. constricta at different salinity levels and time points are shown in Figure 5B. The difference in ACP activity between the control group $\left(S_{20}\right)$ and $S_{30}$ was insignificant. In $\mathrm{S}_{40}$, ACP activity increased first with time, reached the highest value of $2.32 \pm 0.17 \mathrm{U} \cdot \mathrm{mg}^{-1}$ at $12 \mathrm{~h}$, and then decreased sharply and continuously to the lowest value from 12 to $120 \mathrm{~h}$, only accounting for $32.08 \%$ of that at $0 \mathrm{~h}$. Also note that the ACP activity of $\mathrm{S}_{40}$ group was significantly higher than those of control group and $S_{30}$ at 6,12 , and $24 \mathrm{~h}(P<0.05)$. After $96 \mathrm{~h}$, the ACP activity of $\mathrm{S}_{40}$ group was significantly lower than those of the control group and $S_{30}(P<0.05)$.

The variation characteristics of AKP activity with time and salinity were relatively complex (Figure 5C). In the control group, the AKP activity remained stable with time. In group $\mathrm{S}_{30}$, the AKP activity decreased with time and reached the lowest level of $0.31 \pm 0.06 \mathrm{U} \cdot \mathrm{mg}^{-1}$ at $24 \mathrm{~h}(P<0.05)$, after which the value fluctuated slightly and then remained unchanged from 96 to $120 \mathrm{~h}$. In group $\mathrm{S}_{40}$, AKP activity increased with time, reached the highest level of $0.31 \pm 0.06 \mathrm{U} \cdot \mathrm{mg}^{-1}$ at $12 \mathrm{~h}(P<0.05)$, and then significantly decreased and continued to decline until $120 \mathrm{~h}$ $(P<0.05)$. 


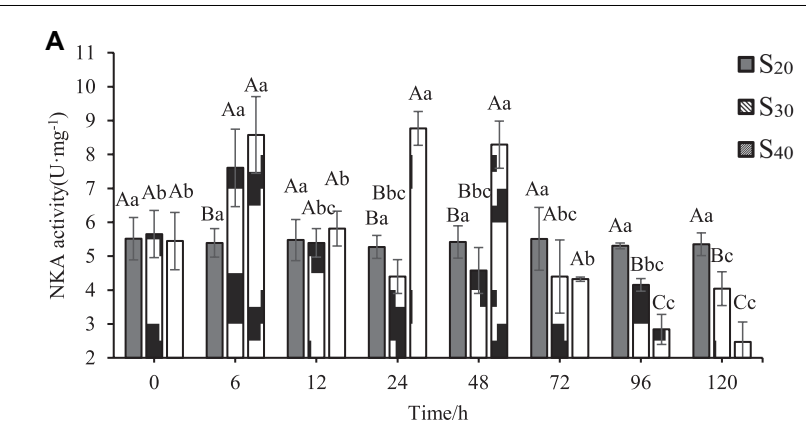

B

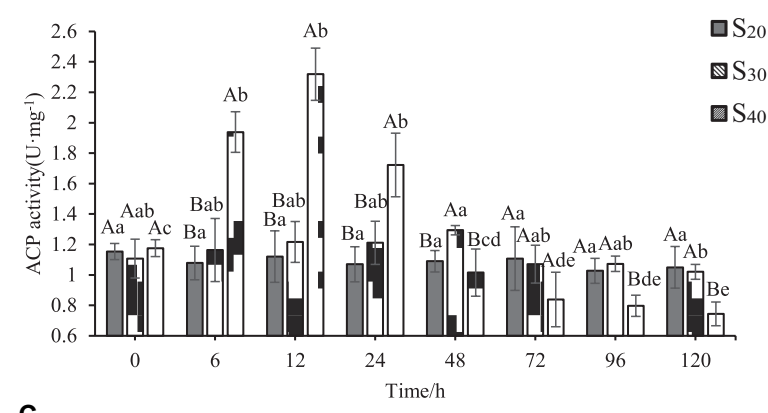

C

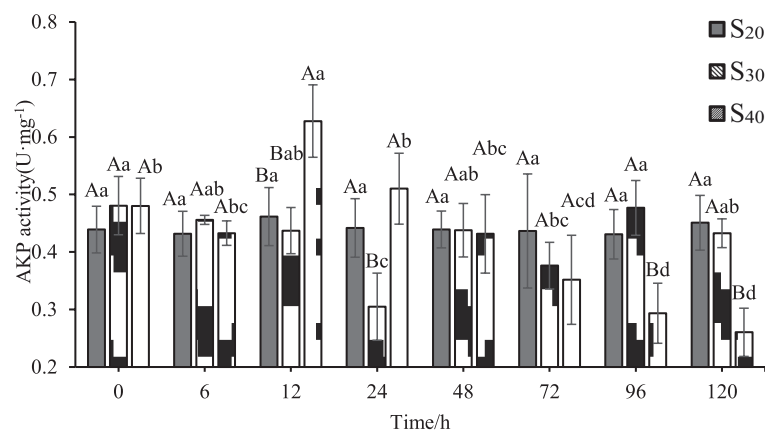

FIGURE 5 | Enzyme activities in gill of Sinonovacula constricta at different salinities and time points. (A) NKA activity, (B) ACP activity, and (C) AKP activity. Different capital letters represent significant differences between groups treated with different salinity levels at the same time point $(P<0.05)$, and different small letters represent significant differences between different time points for the same group $(P<0.05)$.

\section{Changes of Free Amino Acid Contents in Response to Salinity Stress}

In this study, we detected the contents of 18 FAAs in the gill tissue of $S_{20}, S_{30}$, and $S_{40}$ at $48 \mathrm{~h}$ (Table 3). The contents of total FAAs (TFAAs) in the gill tissue of $S_{20}, S_{30}$ and $S_{40}$ were $61.25 \pm 1.58$, $89.36 \pm 4.18$, and $111.98 \pm 1.46 \mathrm{mg} \cdot \mathrm{g}^{-1}$, respectively, indicating an upward tendency with increasing salinity. In the control group $\mathrm{S}_{20}$, taurine, glycine, glutamic and alanine were the major species among the detected FAAs with taurine showing the highest content $\left(26.75 \pm 0.29 \mathrm{mg} \cdot \mathrm{g}^{-1}\right)$, whereas cysteine showed the lowest content of $0.02 \pm 0.03 \mathrm{mg} \cdot \mathrm{g}^{-1}$. The contents of most FAAs in $S$. constricta changed under salinity stress. Compared with those of the group $S_{20}$, the glycine, alanine, cysteine, methionine, leucine, tyrosine, phenylalanine, histidine, and proline contents
TABLE 3 | The contents of free amino acids (FAAs) in the gill tissue of Sinonovacula constricta at different salinities $\left(\mathrm{mg} \cdot \mathrm{g}^{-1}\right.$, mean $\pm \mathrm{SD}$ ).

\begin{tabular}{lccc}
\hline FAAs & Content in $\mathbf{S}_{\mathbf{2 0}}$ & Content in $\mathbf{S}_{\mathbf{3 0}}$ & Content in $\mathbf{S}_{\mathbf{4 0}}$ \\
\hline Taurine & $26.75 \pm 0.29^{\mathrm{b}}$ & $26.50 \pm 1.49^{\mathrm{b}}$ & $31.22 \pm 1.20^{\mathrm{a}}$ \\
Aspartic & $2.12 \pm 0.10^{\mathrm{a}}$ & $1.92 \pm 0.16^{\mathrm{a}}$ & $1.26 \pm 1.17^{\mathrm{a}}$ \\
Threonine & $0.41 \pm 0.16^{\mathrm{b}}$ & $0.26 \pm 0.03^{\mathrm{b}}$ & $1.53 \pm 0.04^{\mathrm{a}}$ \\
Serine & $0.57 \pm 0.11^{\mathrm{b}}$ & $0.73 \pm 0.05^{\mathrm{b}}$ & $1.69 \pm 0.01^{\mathrm{a}}$ \\
Glutamic & $6.63 \pm 0.20^{\mathrm{b}}$ & $7.02 \pm 0.52^{\mathrm{b}}$ & $9.09 \pm 0.16^{\mathrm{a}}$ \\
Glycine & $9.84 \pm 0.53^{\mathrm{b}}$ & $17.14 \pm 1.03^{\mathrm{a}}$ & $16.66 \pm 0.05^{\mathrm{a}}$ \\
Alanine & $5.00 \pm 0.75^{\mathrm{c}}$ & $18.49 \pm 0.54^{\mathrm{b}}$ & $35.78 \pm 1.06^{\mathrm{a}}$ \\
Cysteine & $0.02 \pm 0.03^{\mathrm{c}}$ & $1.70 \pm 0.12^{\mathrm{a}}$ & $0.41 \pm 0.16^{\mathrm{b}}$ \\
Valine & $0.27 \pm 0.02^{\mathrm{b}}$ & $0.40 \pm 0.01^{\mathrm{b}}$ & $1.6 \pm 0.16^{\mathrm{a}}$ \\
Methionine & $0.75 \pm 0.17^{\mathrm{b}}$ & $2.00 \pm 0.36^{\mathrm{a}}$ & $0.49 \pm 0.04^{\mathrm{b}}$ \\
Isoleucine & $1.51 \pm 0.20^{\mathrm{ab}}$ & $2.21 \pm 0.46^{\mathrm{a}}$ & $0.86 \pm 0.10^{\mathrm{b}}$ \\
Leucine & $0.95 \pm 0.20^{\mathrm{b}}$ & $1.57 \pm 0.08^{\mathrm{a}}$ & $1.29 \pm 0.16^{\mathrm{ab}}$ \\
Tyrosine & $1.11 \pm 0.10^{\mathrm{b}}$ & $2.58 \pm 0.32^{\mathrm{a}}$ & $1.41 \pm 0.28^{\mathrm{b}}$ \\
Phenylalanine & $0.52 \pm 0.19^{\mathrm{b}}$ & $1.47 \pm 0.09^{\mathrm{a}}$ & $1.54 \pm 0.05^{\mathrm{a}}$ \\
Lysine & $1.40 \pm 0.02^{\mathrm{a}}$ & $0.78 \pm 0.03^{\mathrm{b}}$ & $1.13 \pm 0.20^{\mathrm{a}}$ \\
Histidine & $1.20 \pm 0.09^{\mathrm{b}}$ & $1.77 \pm 0.13^{\mathrm{a}}$ & $0.73 \pm 0.03^{\mathrm{c}}$ \\
Arginine & $2.13 \pm 0.15^{\mathrm{b}}$ & $1.74 \pm 0.09^{\mathrm{b}}$ & $3.10 \pm 0.22^{\mathrm{a}}$ \\
Proline & $0.07 \pm 0.00^{\mathrm{c}}$ & $1.08 \pm 0.03^{\mathrm{b}}$ & $2.17 \pm 0.12^{\mathrm{a}}$ \\
Total & $61.25 \pm 1.58^{\mathrm{c}}$ & $89.36 \pm 4.18^{\mathrm{b}}$ & $111.98 \pm 1.46^{\mathrm{a}}$ \\
\hline
\end{tabular}

Different superscript letters in the same column mean significant difference $(P<0.05)$.

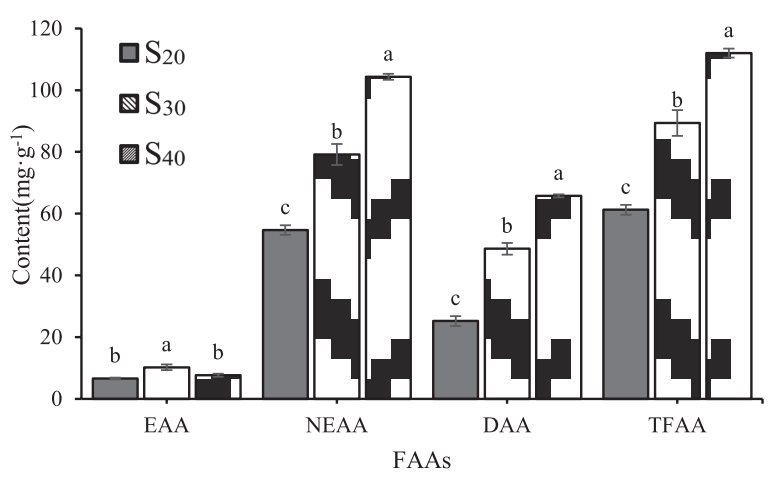

FIGURE 6 | Concentrations of EAAs, NEAAs and DAAs in the gill tissue of Sinonovacula constricta under different salinities. EAAs, essential amino acids; NEAAs, non-essential amino acids; DAAs, delicious amino acids. The different letters mean significant difference $(P<0.05)$.

of $\mathrm{S}_{30}$ were significantly higher $(P<0.05)$. Compared with those of groups $S_{30}$ and $S_{20}$, the contents of taurine, threonine, serine, glutamic, alanine, valine, arginine, and proline in $\mathrm{S}_{40}$ were significantly higher $(P<0.05)$.

Furtherly, we analyzed the contents of essential amino acids (EAAs, include lysine, phenylalanine, methionine, isoleucine, leucine, valine and histidine), non-essential amino acids (NEAAs) and delicious amino acids (DAAs, representing amino acids that contribute to flavor formation, include glutamic, aspartic, phenylalanine, alanine, glycine, and tyrosine) of $S_{20}$, $S_{30}$, and $S_{40}$ (Figure 6). Results showed that the contents of NEAAs and DAAs had the same tendency as the TFAA content with salinity: $S_{40}>S_{30}>S_{20}$. However, the EAA content showed different trend with salinity. The EAA content of $S_{30}$ was 
significantly higher than those of $\mathrm{S}_{20}$ and $\mathrm{S}_{40}$, and there was no significant difference in EAA content between $S_{20}$ and $S_{40}$.

Taurine and proline are two NEAAs. In $S_{20}$ and $S_{30}$, taurine was the most abundant amino acid among all detected FAAs and accounted for 43.67 and $29.66 \%$ of the TFAA content, respectively. In $\mathrm{S}_{40}$, taurine content was significantly higher than those in $S_{30}$ and $S_{20}$ groups. In addition, the proline contents of $S_{20}, S_{30}$ and $S_{40}$ were $0.07 \pm 0.00,1.08 \pm 0.03$, and $2.17 \pm 0.12 \mathrm{mg} \cdot \mathrm{g}^{-1}$, respectively, indicating an upward trend with salinity. In this study, the contents of six DAAs including alanine, glycine, glutamate, aspartic, tyrosine and phenylalanine were detected. Among all the FAAs, alanine showed the greatest increase in content with increasing salinity. In $\mathrm{S}_{20}, \mathrm{~S}_{30}$ and $\mathrm{S}_{40}$, the alanine content accounted for $19.83,38.03$, and $54.43 \%$ of the DAA content, respectively, which suggested that it might contribute greatly to the flavor formation. Notably, in $\mathrm{S}_{40}$, alanine was also the most abundant amino acid among all detected FAAs and accounted for $31.95 \%$ of the TFAA content. In addition to alanine, the contents of another two amino acids glycine and glutamate also increased with salinity, but to a less extent than that of alanine content. The contents of the remaining three DAAs aspartic, tyrosine and phenylalanine were very low.

\section{DISCUSSION}

As an estuarine bivalve, S. constricta naturally encounters drastic changes in water environment. Research suggests that the razor clam is a species with strong adaptation to environmental variations, including salinity changes (Peng et al., 2019). However, when the salinity level varies beyond a certain range, the metabolism in the organism will be disturbed, which can eventually lead to death. Results of this study indicated that high salinity challenge could significantly reduce the survival rate. The death occurred after only $12 \mathrm{~h}$ of treatment with salinity of $40 \mathrm{ppt}$, and the mortality rate increased further with the extension of stress time. In particular, the mortality rates treated with salinity levels of 40 and $45 \mathrm{ppt}$ were up to 86.7 and $100 \%$ at $168 \mathrm{~h}$, respectively. It was thus inferred that salinity above $35 \mathrm{ppt}$ might cause great harm to $S$. constricta even in a short time. The $L C_{50}$ of salinity is an important index to measure the salinity tolerance of an organism. The Karber, linear regression and probit analysis are three major methods for calculating $L C_{50}$ of salinity (Li et al., 2012). For the Karber method, groups with 0 and $100 \%$ mortality rates are necessary to access the $L C_{50}$ for one time point ( $\mathrm{Li}$ et al., 2012). In this study, the mortality data at most sampling time points could not satisfy the above-mentioned requirement, thus the Karber method was abandoned. Although both linear regression and probit analysis have their own advantages and disadvantages, the $L C_{50}$ of salinity calculated by the two methods in this study were similar, which confirmed the reliability of the results. In this experiment, the salinity $L C_{50}$ of $S$. constricta for $72 \mathrm{~h}$ treatment calculated by the probit analysis and linear regression were 46.26 and $44.31 \mathrm{ppt}$, respectively, suggesting that razor clam might have some ability to tolerate high salinity stress.

Gill is an important organ in response to environmental changes including changes of salinity, temperature, $\mathrm{pH}$, etc.
(Allen et al., 2011). The histopathological alterations of gill can be used as an adaptation marker after acclimation to new salinity conditions (DiMaggio et al., 2009). In this study, the gill structure of razor clam was found to change significantly under acute salinity stress. Specifically, compared with those treated with 20 ppt salinity, razor clams treated with 30 and 40 ppt salinity showed shrunk gill filaments and decreased gill thickness. It was concluded that $S$. constricta might respond to salinity stress by actively changing the morphology of gill tissue. Specifically, the shrinkage of gill filaments and reduction of gill thickness helped to effectively reduce the contact area between gill and high salt water, and thus preserve water in vivo. The changes of GFL, GFW, and GT were also consistent with the above results. The minimum GFL, GFW, and GT of $\mathrm{S}_{30}$ accounted for 83.04, 76.64, and $58.55 \%$ of those of the control group, and those of $\mathrm{S}_{40}$ accounted for $70.96,59.53$, and $57.88 \%$ of those of the control group. These data further corroborated our results. The gill tissue did not dissolve at $30 \mathrm{ppt}$. It was speculated that $S$. constricta may adapt to salinity of $30 \mathrm{ppt}$ in a short time through activating osmotic adjustment. At salinity of $40 \mathrm{ppt}$, however, the gill structure began to change after $48 \mathrm{~h}$, indicating that $S$. constricta could not adapt to this salinity in a short time.

Osmoregulation is a complex physiological process, and for the gill cells, sodium and potassium regulation are mainly mediated by NKA (Peng et al., 2019). As an important active component of $\mathrm{Na}^{+} / \mathrm{K}^{+}$pump, NKA plays an important role in maintaining the homeostatic state of $\mathrm{Na}^{+}$and $\mathrm{K}^{+}$in cells (Cheng et al., 2002; Palacios et al., 2004; Garçon et al., 2009). It is also the focus of salinity adaptation studies. Some research has found that the NKA activity of spottedtail goby Synechogobius ommaturus firstly increases under high salinity stress, then reaches a peak value at $12 \mathrm{~h}$ and then decreases, which is similar to the results of many studies on fishes (Shui et al., 2018). In this study, the activity of NKA increased first and then decreased to a stable level under high salinity stress. When the salinity changed sharply, the activity of NKA fluctuated greatly in a short time, which was possibly because the razor clam could hardly adapt to the acute salinity changes in a short time. In a later stage of salinity stress, the NKA activity gradually became stable, suggesting that the organism might adapt to the new environmental condition. However, it was worth noting that the stabilized NKA activity under high salinity was significantly lower than that of the control group. Research suggests that there is a certain relationship between salt tolerance and NKA activity (Chen et al., 2021). Our S. constricta has higher NKA activity than that reported by Chen et al. (2021), this means that our S. constricta possibly have higher salt tolerance.

Mollusks lack specific immune cells and related antibodies, thus their humoral immunity mainly depends on some nonspecific enzymes or factors in serum (Muta and Iwanaga, 1996; Yang et al., 2021). ACP and AKP are important components of lysosomal enzymes of mollusks, and play a role in their immune response. Salinity stress causes changes in hemolymph osmotic pressure in shellfish, which leads to the response of immune system (Cheng et al., 2002). Studies have shown that changes in salinity can cause changes in various immune indexes of mollusks, such as AKP, catalase (CAT) and superoxide dismutase 
(SOD) levels, thus reducing the immunity of the organism (Chen et al., 2021). This study showed that the ACP and AKP activities changed inconsistently after high salt stress. The ACP activity of $S$. constricta treated with salinity of $30 \mathrm{ppt}$ showed no significant change, while the ACP activity treated with salinity of $40 \mathrm{ppt}$ increased significantly after $12 \mathrm{~h}$ of stress, then decreased and tended to be stable. It may be that at 30 ppt salinity, the homeostasis of the internal environment was maintained through regulation, so its ACP activity did not change significantly. Under the stress of $40 \mathrm{ppt}$ salinity, the internal environment was disturbed. After $12 \mathrm{~h}$ of stress, the activity of NKA decreased significantly, while the activity of ACP increased significantly possibly in order to maintain the homeostasis of the internal environment. The results were similar to those of P. trituberculatus (Zheng et al., 2010). The activity of AKP did not increase significantly after high salt stress, which was similar to the changes of AKP activity of hemolymph in C. ariakensis under high salt stress (Shi et al., 2013). This may be the characteristics of response of estuarine shellfish to high salt stress. It is speculated that under salt stress razor clams regulate enzyme activities to assist in osmoregulation to achieve adaption.

Several FAAs have been reported to involve in osmoregulation in marine invertebrate animals (Shumway et al., 1977; Heavers and Hammen, 1985; Hosoi et al., 2003; Meng et al., 2013; Cheng et al., 2020). Research shows that under osmotic stress razor clam could actively adjust the intracellular osmotic pressure to the osmotic concentration of the seawater, which is called "isosmotic intracellular regulation” (Heavers and Hammen, 1985). The metabolisms of FAAs play an important role in the above regulation process in many aquatic animals, and also in shellfish. In this current study, the content of NEAAs was significantly higher than that of EAAs, and the content of NEAAs was positively correlated with salinity, which was different from the case of EAAs. The results indicated that NEAAs in S. constricta might play a major role in osmoregulation, which was consistent with the results about Chinese mitten crabs Eriocheir sinensis (Wang et al., 2012) and C. gigas (Hosoi et al., 2003). It was interesting to note that DAAs including glutamic, glycine, alanine and phenylalanine all increased significantly in response to high salinity stress in this study. Research has shown that the contents of DAAs in aquatic animals in higher salinity water are higher than those in lower salinity water, and the increased DAA contents contribute to the improvement of flavor.

In many marine mollusks, alanine, glycine, proline, taurine and glutamic are typically the dominant FAAs contributing to intracellular osmolality and the osmoconforming process (Hosoi et al., 2003). In this study, the contents of the above-mentioned FAAs also became higher in S. constricta when salinity increased to $40 \mathrm{ppt}$. Among those FAAs, taurine is considered as an important osmolyte in various animals and generally the most abundant FAA in lots of bivalve species (Lynch and Wood, 1966; Heavers and Hammen, 1985; Hosoi et al., 2003; Meng et al., 2013; Lin et al., 2021). For example, taurine has been found to be of the highest content among the FAAs in oyster, close to $80 \%$ of the content of total amino acids (Hosoi et al., 2003). In this study, taurine accounted for approximately $44 \%$ of the total FAA content in S. constricta treated with salinity of $20 \mathrm{ppt}$, which was consistent with most previous studies. In addition, with the increase of salinity, taurine content increased slowly and possibly substantially contributed to regulation of osmolality for high salinity adaptation. In addition to taurine, some other FAAs including glycine, alanine, proline and aspartic were also likely involved in the adaptation process under high salinity stress. The contents of glycine, alanine, and proline increased with salinity, and alanine was the most sensitive FAA to high salinity, since its content increased approximately by three and six times when salinity changed from 20 to $30 \mathrm{ppt}$ and $40 \mathrm{ppt}$, respectively. The possible reason was that the de novo synthesis of alanine requires less energy than that of other FAAs and there exist many pathways for its synthesis via transamination to pyruvate (Hosoi et al., 2003).

\section{CONCLUSION}

Combining all the results, we clearly demonstrated that the response of $S$. constricta to high salinity stress was multidimension. With the increase of salinity and the extension of stress time, the mortality, gill tissue structure, enzymes activity and free amino acid contents of razor clam all changed significantly. On the above basis, it was inferred that the razor clam may adapt to salinity of $30 \mathrm{ppt}$ in a short time through activating osmotic adjustment. A small proportion of razor clam could survive under the salinity of $35 \mathrm{ppt}$, but the death of many individuals definitely means great loss in aquacultural production. Notable, living in a salinity of $40 \mathrm{ppt}$ for more than $48 \mathrm{~h}$ would cause great damage to razor clams. Therefore, we recommended seawater salinity should be lower than $30 \mathrm{ppt}$ for cultivating. In conclusion, this study enhances our understanding of $S$. constricta in response to high salt stress, and provides useful information for breeding new high-salt tolerant species and the further culture.

\section{DATA AVAILABILITY STATEMENT}

The original contributions presented in the study are included in the article/supplementary material, further inquiries can be directed to the corresponding author/s.

\section{AUTHOR CONTRIBUTIONS}

BW, WC, and SB contributed to conception and design of the study. BW and WC wrote the first draft of the manuscript. BW, WC, SB, and YG wrote sections of the manuscript. All authors contributed to manuscript revision, read, and approved the submitted version.

\section{FUNDING}

We would like to thank the financial supports from Ningbo Major Project of Science and Technology (2019B10005), Major Scientific and Technological Innovation Project of Shandong Province (2019JZZY020706), and National Marine Genetic Resource Center. 


\section{REFERENCES}

Allen, P. J., McEnroe, M., Forostyan, T., Cole, S., Nicholl, M. M., Hodge, B., et al. (2011). Ontogeny of salinity tolerance and evidence for seawater-entry preparation in juvenile green sturgeon, Acipenser medirostris. J. Comp. Physiol. B 181, 1045-1062. doi: 10.1007/s00360-011-0592-0

Berger, V. J., and Kharazova, A. D. (1997). Mechanisms of salinity adaptations in marine molluscs. Hydrobiologia 355, 115-126. doi: 10.1023/A:1003023322263

Carregosa, V., Figueira, E., Gil, A. M., Pereira, S., Pinto, J., Soares, A. M. V. M., et al. (2014). Tolerance of Venerupis philippinarum to salinity: osmotic and metabolic aspects. Comp. Biochem. Physiol. Part A Mol. Integr. Physiol. 171, 36-43. doi: 10.1016/j.cbpa.2014.02.009

Chen, Y., Ye, B., Niu, D., and Li, J. (2021). Changes in metabolism and immunity in response to acute salinity stress in Chinese razor clams from different regions. Aquac. Rep. 19:100624. doi: 10.1016/j.aqrep.2021.100624

Cheng, W., Yeh, S., Wang, C., and Chen, J. (2002). Osmotic and ionic changes in Taiwan abalone Haliotis diversicolor supertexta at different salinity levels. Aquaculture 203, 349-357. doi: 10.1016/S0044-8486(01)00606-8

Cheng, Y., Zhao, J., Ayisi, C. L., and Cao, X. (2020). Effects of salinity and alkalinity on fatty acids, free amino acids and related substance anabolic metabolism of Nile tilapia. Aquac. Fish. doi: 10.1016/j.aaf.2020.06.005

DiMaggio, M. A., Ohs, C. L., and Petty, B. D. (2009). Salinity tolerance of the Seminole killifish, Fundulus seminolis, a candidate species for marine baitfish aquaculture. Aquaculture 293, 74-80. doi: 10.1016/j.aquaculture.2009.04.009

Gagnaire, B., Frouin, H., Moreau, K., Thomas-Guyon, H., and Renault, T. (2006). Effects of temperature and salinity on haemocyte activities of the Pacific oyster, Crassostrea gigas (Thunberg). Fish Shellfish Immunol. 20, 536-547. doi: 10.1016/ j.fsi.2005.07.003

Gao, B., Sun, D., Lv, J., Ren, X., Liu, P., and Li, J. (2019). Transcriptomic analysis provides insight into the mechanism of salinity adjustment in swimming crab Portunus trituberculatus. Genes Genomics 41, 961-971. doi: 10.1007/s13258019-00828-4

Garçon, D. P., Masui, D. C., Mantelatto, F. L. M., Furriel, R. P. M., McNamara, J. C., and Leone, F. A. (2009). Hemolymph ionic regulation and adjustments in gill $(\mathrm{Na}+, \mathrm{K}+)$-ATPase activity during salinity acclimation in the swimming crab Callinectes ornatus (Decapoda, Brachyura). Comp. Biochem. Physiol. Part A Mol. Integr. Physiol. 154, 44-55. doi: 10.1016/j.cbpa.2009.04.624

Heavers, B. W., and Hammen, C. S. (1985). Fate of endogenous free amino acids in osmotic adjustment of Crassostrea virginica (Gmelin). Comp. Biochem. Physiol. Part A Mol. Integr. Physiol. 82, 571-576. doi: 10.1016/0300-9629(85)90435-9

Hoekstra, J. A. (1991). Estimation of the $\mathrm{LC}_{50}$, a review. Environmetrics (London, Ont.) 2, 139-152. doi: 10.1002/env.3770020203

Hosoi, M., Kubota, S., Toyohara, M., Toyohara, H., and Hayashi, I. (2003). Effect of salinity change on free amino acid content in Pacific oyster. Fish. Sci. 69, 395-400. doi: 10.1046/j.1444-2906.2003.00634.x

Kumari, S., Harikrishna, V., Surasani, V. K. R., Balange, A. K., and Babitha Rani, A. M. (2021). Growth, biochemical indices and carcass quality of red tilapia reared in zero water discharge based biofloc system in various salinities using inland saline ground water. Aquaculture 540:736730. doi: 10.1016/j. aquaculture.2021.736730

Lange, R. (1963). The osmotic function of amino acids and taurine in the mussel, Mytilus edulis. Comp. Biochem. Physiol. 10, 173-179. doi: 10.1016/0010406x(63)90239- 1

Laverty, G., and Skadhauge, E. (2012). Adaptation of teleosts to very high salinity. Comp. Biochem. Physiol. Part A Mol. Integr. Physiol. 163, 1-6. doi: 10.1016/j. cbpa.2012.05.203

Li, C., Wu, M., and Wang, H. (2012). LC50 caculated by kochi, probit analysis and linear regression methods. Prog. Vet. Med. 33, 89-92. doi: 10.16437/j.cnki.10075038.2012.09.012

Li, Y., Niu, D., Wu, Y., Dong, Z., and Li, J. (2021). Integrated analysis of transcriptomic and metabolomic data to evaluate responses to hypersalinity stress in the gill of the razor clam (Sinonovacula constricta). Comp. Biochem. Physiol. Part D Genomics Proteomics 38:100793. doi: 10.1016/j.cbd.2021.100793

Lin, C. H., Tsai, R. S., and Lee, T. H. (2004). Expression and distribution of $\mathrm{Na}, \mathrm{K}$-ATPase in gill and kidney of the spotted green pufferfish, Tetraodon nigroviridis, in response to salinity challenge. Comp. Biochem. Physiol. Part A Mol. Integr. Physiol. 138, 287-295. doi: 10.1016/j.cbpb.2004.04.005
Lin, C. H., Yeh, P. L., and Lee, T. H. (2021). Time-course changes in the regulation of ions and amino acids in the hard clam Meretrix lusoria upon lower salinity challenge. J. Exp. Zool. Part A Ecol. Integr. Physiol. 335, 602-613. doi: 10.1002/ jez. 2503

Luo, J., Monroig, Ó, Zhou, Q., Tocher, D. R., Yuan, Y., Zhu, T., et al. (2021). Environmental salinity and dietary lipid nutrition strategy: effects on flesh quality of the marine euryhaline crab Scylla paramamosain. Food Chem. 361:130160. doi: 10.1016/j.foodchem.2021.130160

Luzio, A., Parra, S., Costa, B., Santos, D., Álvaro, A. R., and Monteiro, S. M. (2021). Copper impair autophagy on zebrafish (Danio rerio) gill epithelium. Environ. Toxicol. Phar. 86:103674. doi: 10.1016/j.etap.2021.103674

Lynch, M. P., and Wood, L. (1966). Effects of environmental salinity of free amino acids of Crassostrea virginica gmelin. Comp. Biochem. Physiol. 19, 783-790. doi: 10.1016/0010-406X(66)90434-8

Meng, J., Zhu, Q., Zhang, L., Li, C., Li, L., She, Z., et al. (2013). Genome and transcriptome analyses provide insight into the euryhaline adaptation mechanism of Crassostrea gigas. PLoS One 8:e58563. doi: 10.1371/journal.pone. 0058563

Munari, M., Matozzo, V., and Marin, M. G. (2011). Combined effects of temperature and salinity on functional responses of haemocytes and survival in air of the clam Ruditapes philippinarum. Fish Shellfish Immunol. 30, 1024-1030. doi: 10.1016/j.fsi.2011.01.025

Muta, T., and Iwanaga, S. (1996). The role of hemolymph coagulation in innate immunity. Curr. Opin. Immunol. 8, 41-47. doi: 10.1016/S0952-7915(96)801038

Palacios, E., Bonilla, A., Luna, D., and Racotta, I. S. (2004). Survival, Na+/K+ATPase and lipid responses to salinity challenge in fed and starved white pacific shrimp (Litopenaeus vannamei) postlarvae. Aquaculture 234, 497-511. doi: 10.1016/j.aquaculture.2003.12.001

Pechenik, J. A., Berard, R., and Kerr, L. (2000). Effects of reduced salinity on survival, growth, reproductive success, and energetics of the euryhaline polychaete Capitella sp. I. J. Exp. Mar. Biol. Ecol. 254, 19-35. doi: 10.1016/s00220981(00)00261-6

Peng, M., Liu, X., Niu, D., Ye, B., Lan, T., Dong, Z., et al. (2019). Survival, growth and physiology of marine bivalve (Sinonovacula constricta) in long-term low-salt culture. Sci. Rep. UK 9:2819. doi: 10.1038/s41598-019-39205-2

Ran, Z., Li, S., Zhang, R., Xu, J., Liao, K., Yu, X., et al. (2017). Proximate, amino acid and lipid compositions in Sinonovacula constricta (Lamarck) reared at different salinities. J. Sci. Food Agric. 97, 4476-4483. doi: 10.1002/jsfa.8311

Shen, M., Cui, Y., Wang, R., Dong, T., Ye, H., Wang, S., et al. (2020). Acute response of Pacific white shrimp Litopenaeus vannamei to high-salinity reductions in osmosis-, metabolism-, and immune-related enzyme activities. Aquac. Int. 28, 31-39. doi: 10.1007/s10499-019-00441-y

Shi, S., Wang, R., Wang, J., Jiang, J., Liu, G., and Yang, R. (2013). Effects of salinity stress on immune factors of Crassostrea hongkongensis. South China Fish. Sci. 9, 26-30. doi: 10.3969/j.issn.2095-0780.2013.03.005

Shui, C., Shi, Y., Hua, X., Zhang, Z., Zhang, H., Lu, G., et al. (2018). Serum osmolality and ions, and gill $\mathrm{Na}+/ \mathrm{K}+$-ATPase of spottedtail goby Synechogobius ommaturus (R.) in response to acute salinity changes. Aquac. Fish. 3, 79-83. doi: 10.1016/j.aaf.2018.03.002

Shumway, S. E., Gabbott, P. A., and Youngson, A. (1977). The effect of fluctuating salinity on the concentrations of free amino acids and ninhydrin-positive substances in the adductor muscles of eight species of bivalve Molluscs. J. Exp. Mar. Biol. Ecol. 29, 131-150. doi: 10.1016/0022-0981(77)90044-2

Vargas-Chacoff, L., Saavedra, E., Oyarzún, R., Martínez-Montaño, E., Pontigo, J. P., Yáñez, A., et al. (2015). Effects on the metabolism, growth, digestive capacity and osmoregulation of juvenile of Sub-Antarctic Notothenioid fish Eleginops maclovinus acclimated at different salinities. Fish Physiol. Biochem. 41, 1369-1381. doi: 10.1007/s10695-015-0092-3

Wang, Y., and $\mathrm{Hu}, \mathrm{X}$. (2009). Microscopical observation on the gill structure of juvenile Lateolabrax japonicus under different salinities. Mar. Sci. 33, 138-142.

Wang, Y., Hu, W., Li, J., Huang, X., Duan, L., and Zhan, Y. (2016). Effects of acute salinity stress on gill structure and four enzyme activities in Saxidomus purpurata. J. Agric. Sci. Technol. 18, 178-186. doi: 10.13304/j.nykjdb.2015.732

Wang, Y., Li, E., Yu, N., Wang, X., Cai, C., Tang, B., et al. (2012). Characterization and expression of glutamate dehydrogenase in response to acute salinity stress 
in the Chinese mitten crab, Eriocheir sinensis. PLoS One 7:e37316. doi: 10.1371/ journal.pone.0037316

Yang, W., Hseu, J., Tang, C., Chung, M., Wu, S., and Lee, T. (2009). Na+/K+ATPase expression in gills of the euryhaline sailfin molly, Poecilia latipinna, is altered in response to salinity challenge. J. Exp. Mar. Biol. Ecol. 375, 41-50. doi: 10.1016/j.jembe.2009.05.004

Yang, W., Tran, N. T., Zhu, C., Yao, D., Aweya, J. J., Gong, Y., et al. (2021). Immune priming in shellfish: a review and an updating mechanistic insight focused on cellular and humoral responses. Aquaculture 530:735831. doi: 10. 1016/j.aquaculture.2020.735831

Zhang, M., Wang, L., Wang, B., Liu, M., Zhang, W., and Jiang, K. (2017). cDNA cloning and gene expressionin response to salinity of alkaline phosphatase and acid phosphatase from Litopenaeus vannamei. Mar. Sci. 41, 83-95. doi: 10.11759//hykx20160112002

Zheng, P., Wang, C., Song, W., and Wu, D. (2010). Effect of salinity stress on serum non-specific immune factors in swimming crab Portunus trituberculatus. Fish. Sci. 29, 634-638. doi: 10.16378/j.cnki.1003-1111.2010.11.005
Conflict of Interest: The authors declare that the research was conducted in the absence of any commercial or financial relationships that could be construed as a potential conflict of interest.

Publisher's Note: All claims expressed in this article are solely those of the authors and do not necessarily represent those of their affiliated organizations, or those of the publisher, the editors and the reviewers. Any product that may be evaluated in this article, or claim that may be made by its manufacturer, is not guaranteed or endorsed by the publisher.

Copyright (c) 2022 Cao, Bi, Chi, Dong, Xia, Liu, Zhou, Sun, Geng and Wu. This is an open-access article distributed under the terms of the Creative Commons Attribution License (CC BY). The use, distribution or reproduction in other forums is permitted, provided the original author(s) and the copyright owner(s) are credited and that the original publication in this journal is cited, in accordance with accepted academic practice. No use, distribution or reproduction is permitted which does not comply with these terms. 